\title{
Sistem Informasi Akademik Berbasis Web Menggunakan Model Waterfall Pada SMK ITENAS Karawang
}

\author{
Siti Masturoh ${ }^{1}$, Diah Wijayanti $^{2}$, Arfhan Prasetyo $^{3}$ \\ ${ }^{1}$ STMIK Nusa Mandiri \\ e-mail: sitimasturoh2707@gmail.com \\ ${ }^{2}$ Universitas Bina Sarana Informatika \\ e-mail: diah.dhw@bsi.ac.id \\ ${ }^{3}$ Universitas Bina Sarana Informatika \\ e-mail: arfhan.afp@bsi.ac.id
}

\begin{abstract}
Abstrak
SMK ITENAS Karawang merupakan sebuah bentuk perwujudan dalam mendidik genarasi muda bangsa Indonesia. Dengan perkembangan jumlah siswa yang terus bertambah dari tahun ke tahun, dituntut ketepatan dan ketelitian dalam memberikan informasi yang tepat dan akurat kepada siswa tanpa adanya pengulangan data yang sama. SMK ITENAS karawang sangat membutuhkan adanya sebuah sistem informasi yang menunjang dalam proses penyajian informasi akademik sekolah. Untuk itu penulis mencoba menangani masalah tersebut dengan merancang suatu Sistem Informasi Akademik Berbasis Web Pada SMK ITENAS karawang. Sistem informasi akademik merupakan salah satu solusi untuk memberikan sebuah informasi secara cepat, tepat dan akurat. sistem informasi akademik berbasis web sangat berguna dalam memberikan kemudahan baik kepada pengajar ataupun pelajar. Sistem Informasi Akademik Berbasis Web merupakan solusi yang tepat untuk mewujudkan sebuah sistem informasi yang efektif dan efisien.

Kata Kunci: Sistem Informasi Berbasis Web
\end{abstract}

\begin{abstract}
SMK ITENAS karawang is a form of embodiment in educating the young generation of Indonesia. With the development of a growing number of students from year to year, required precision and accuracy in providing precise and accurate information for students without the repetition of the same data. SMK ITENAS karawang so requires an information system that supports the presentation of the school's academic information. To the authors tried to handle the problem by designing a Web-Based Information System Academic In SMK ITENAS karawang. Academic information system is one solution to provide an information quickly and accurately. web-based academic information system is very useful in providing convenience to both the teacher or the student. Web-Based Academic Information System is the perfect solution to create an information system that is effective and efficient.
\end{abstract}

Keywords: Web-Based Information System 


\section{Pendahuluan}

Pengelolaan informasi yang cepat, tepat dan akurat di nilai sangat peting karena dapat membantu berkembangnya sebuah lembaga maupun instansi. Salah satu bentuk implementasi sistem informasi yang cepat, tepat dan akurat ini adalah sistem informasi berbasis website yang memanfaatkan teknologi komputer dan teknologi internet.

SMK Industri Teknologi Nasional (ITENAS) Karawang merupakan salah satu instansi pemerintah di bidang pendidikan yang terletak di jalan raya pedes sungaibuntu desa payungsari kecamatan pedes kabupaten karawang. SMK Industri Teknologi Nasional (ITENAS) Karawang saat ini memiliki jumlah siswa 900. SMK Industri Teknologi Nasional (ITENAS) Karawang belum mempunyai sistem informasi akademik, sehingga pengolahan data siswa, pembagian kelas, penjadwalan hingga penilaian masih menggunakan buku atau arsip sehingga memungkinkan terjadinya kesalahan data dan kerangkapan data.

Permasalahan yang teridentifkasi pada SMK Industri Teknologi Nasional (ITENAS) Karawang adalah sebagai berikut:

a. SMK Industri Teknologi Nasional (ITENAS) karawang belum mempunyai sistem informasi akademik khususnya pengolahan data nilai yang efektif dan efisien. Dalam artian semua informasi baik untuk guru ataupun siswa masih menggunakan sistem manual.

b. Belum adanya sistem yang khusus untuk membuat jadwal pelajaran sehingga memerlukan waktu yang banyak untuk membuat jadwal pelajaran tersebut.

Untuk menunjang dalam proses informasi akademik sekolah kepada siswa dibutuhkannya sistem informasi akademik sekolah berbasis web agar dalam penyampaian informasinya lebih cepat dan tepat, dalam pengolahan jadwal mengajar guru dan pengolahan data nilai siswa lebih cepat di kerjakan di web tersebut.

Untuk mengurangi permasalahan tersebut maka perlu diterapkan sistem informasi akademik pada SMK Industri Teknologi
Nasional (ITENAS) Karawang diharapkan dapat mempermudah bagi staf tata usaha, guru, siswa dan masyarakat untuk mendapatkan informasi secara rinci dan mempermudah dalam melakukan proses pengolahan data siswa maupun nilai.

\section{Metode Penelitian}

\subsection{Teknik Pengumpulan Data}

Metode dalam pengumpulan data ini yaitu menggunakan metode observasi, wawancara dan studi pustaka. Dengan metode ini penulis mengutip sumbersumber data yang sudah tertulis dan jelas sumber datanya guna melengkapi skripsi ini adalah sebagai berikut :

A. Observasi

Penulis melakukan observasi pada SMK Industri Teknologi Nasional (ITENAS) Karawang, dengan maksud agar penulis dapat lebih memahami situasi dan proses pekerjaan yang sebenarnya, mengenai sistem yang sedang berjalan.

B. Wawancara

Selain melakukan observasi penulis juga melakukan wawancara yaitu pengumpulan data dengan mengajukan beberapa pertanyaan kepada pihak sekolah khususnya bagian yang berkaitan dengan sistem yang diteliti yaitu kepala sekolah, bagian kurikulum dan tata usaha.

\section{Studi Pustaka}

Dengan metode studi pustaka ini penulis mendapatkan sumber data dari buku dan makalah yang berhubungan dengan studi literatur pada buku atau referensi yang berkaitan dengan perancangan aplikasi berbasis web.

\subsection{Model Pengembangan Sistem}

Dalam mengembangkan System Development Life Cycle (SDLC) yang merupakan metodologi umum dalam pengembangan sistem yang menandai kemajuan dan usaha analisa dan desain. SDLC yang sering juga disebut sebagai pendekatan air terjun (waterfall) yaitu penggunaan sistem yang memiliki tahapan sebagai berikut:

\section{A. Analisa Kebutuhan Sistem}

Pada tahapan ini penulis mengamati setiap masalah yang ada di SMK Industri Teknologi Nasional (ITENAS) Karawang khususnya masalah pada Sistem Informasi Akademik, kemudian mendefinisikan masalah tersebut. 
Selanjutnya Penulis mendeskripsikan sistem yang sudah berjalan di SMK Industri Teknologi Nasional (ITENAS) Karawang dan kemudian memberikan rekomendasi perbaikan, meningkatkan sistem yang sudah berjalan, dengan pembuatan website ini, sehingga software yang diterapkan bisa berjalan dengan efektif dan efisien. software yang penulis gunakan dalam perancangan web ini adalah script web $P H P$ dengan database MySQL.

B. Desain

Desain perangkat lunak adalah proses multi langkah yang fokus pada desain pembuatan program perangkat lunak termasuk struktur data, arsitektur perangkat lunak, representasi antarmuka dan prosedur pengkodean. Desain dan pembuatan aplikasi berkonsentrasi pada bagaimana sistem dibangun untuk memenuhi kebutuhan pada fase analisis, membangun perangkat lunak untuk mendukung sistem meliputi desain sistem dengan menggunakan ERD, mendesain user interface, manajemen user, manajemen file, membuat rancangan input output dan membuat rancangan keamanan web.

C. Code Generation

Penulis mendeskripsikan pearancangan sistem yang penulis usulkan pada permasalahan yang ada dengan menjabarkan semua perintahperintah listing atau coding yang digunakan untuk pengolahan data yang ada dalam pembuatan Web Sistem Informasi Akademik pada SMK Industri Teknologi Nasional (ITENAS) Karawang yang kemudian dapat dikompile menggunakan server local (localhost).

\section{Testing}

Pengujian program yang sudah dibuat kedalam sistem yang sudah ada merupakan suatu proses pengubahan dari hasil perancangan sistem yang berbasis web PHP, dalam hal ini penulis menggunakan Black Box Testing.

\section{E. Support}

Dalam mengakses website yang penulis buat diperlukan adanya menghosting.Sebagaimana domain, web hosting juga ada yang menyediakan secara gratis dan adapula yang berbayar.

\section{Hasil dan Pembahasan 3.1. Analisa Kebutuhan Software}

A. Tahapan Analisis

Sistem pada SMK Industri teknologi Nasional (ITENAS) Karawang dibuat menjadi sistem informasi Akademik online yang diakses melalui media browser. Berikut ini spesifikasi kebutuhan (System requirement) dari sistem informasi akademik pada SMK Industri Teknologi Nasional (ITENAS) Karawang :

\section{Halaman Pengunjung}

A.1.User dapat melihat home

A.2.User dapat melihat profile

A.3.User dapat melihat berita

A.4. User dapat melihat artikel

A.5.User dapat melihat informasi akademik

A.6.User dapat melihat galeri photo

A.7.User dapat melihat fasilitas

A.8.User dapat mengisi buku tamu

2. Halaman Ruang Admin

B.1.Admin dapat mengelola data Siswa

B.2.Admin dapat mengelola data Guru

B.3.Admin dapat mengelola data mata pelajaran

B.4.Admin dapat mengelola data kelas

B.5.Admin dapat mengelola data pembagian kelas

B.6.Admin dapat mengelola data nilai

B.7.Admin dapat mengelola data jadwal pelajaran

B.8.Admin dapat mengelola data kalender akademik

B.9.Admin dapat mengelola data artikel

B.10. Admin dapat mengelola data berita

B.11. Admin dapat mengelola data buku tamu

3. Halaman Ruang Guru

C.1. Guru dapat melihat data pribadi

C.2. Guru dapat melihat jadwal mengajar

C.3. Guru dapat menginput nilai

C.4. Guru dapat melihat data siswa

C.5. Guru dapat melihat data jadwal mengajar guru

C.6. Guru data melihat data kalender akademik

4. Halaman Ruang Siswa

D.1. Siswa dapat melihat data pribadi siswa

D.2. Siswa dapat melihat nilai raport

D.3. Siswa dapat melihat jadwal pelajaran 
D.4. Siswa dapat melihat data jadwal mengajar guru

D.5. Siswa dapat melihat kalender akademik

B. Use Case Diagram

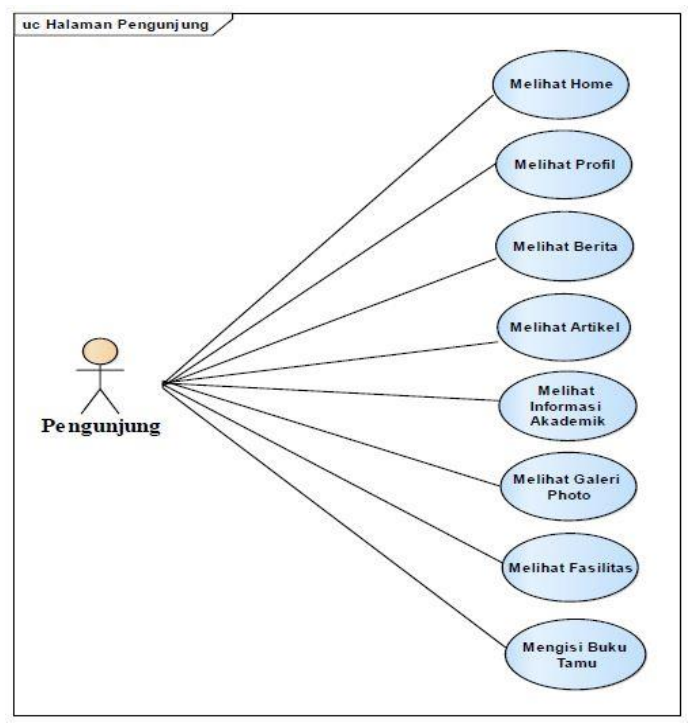

Gambar 1 Use Case Diagram Akademik Sekolah online Halaman Pengunjung

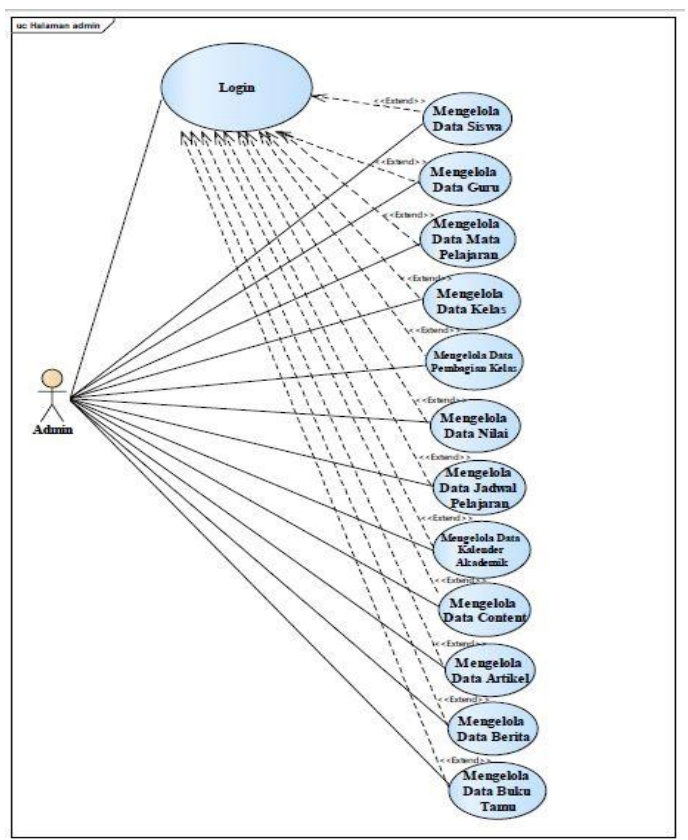

Gambar 2. Use Case Diagram Akademik Sekolah Online Halaman Admin

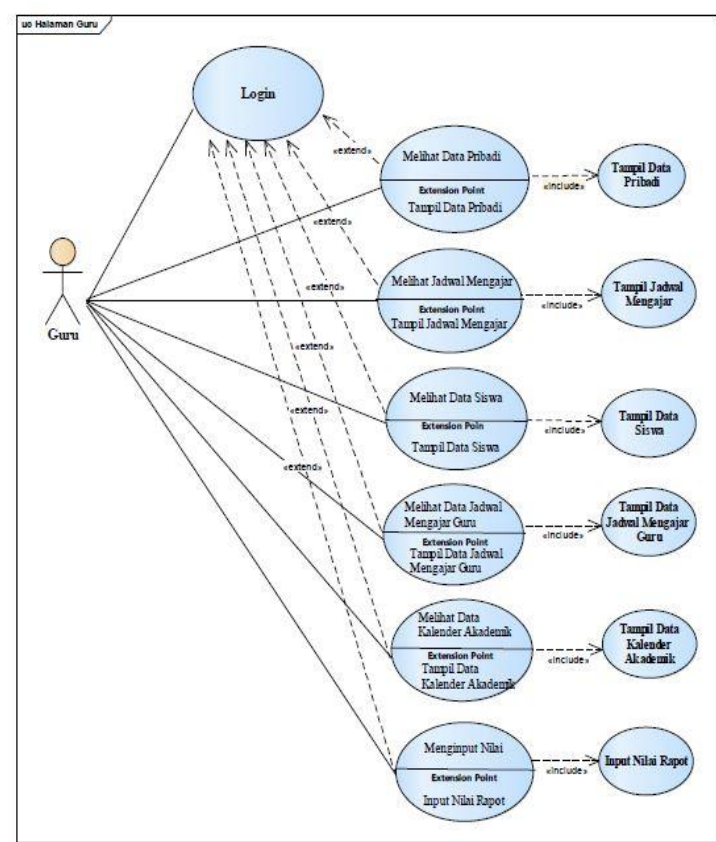

Gambar 3. Use Case Diagram Akademik Sekolah Online Halaman Guru

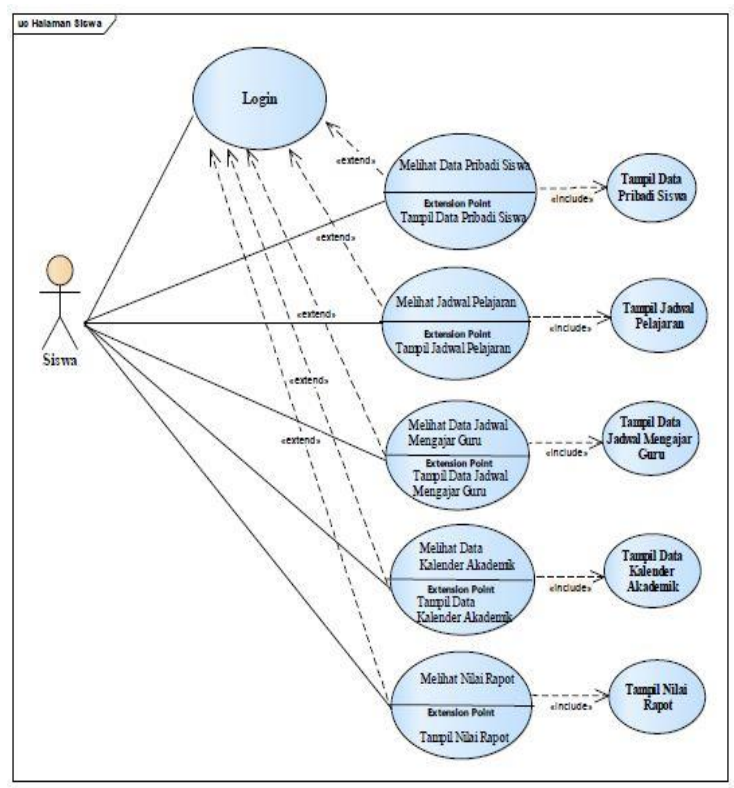

Gambar 4. Use Case Diagram Akademik Sekolah Online Halaman Siswa 
C. Activity Diagram

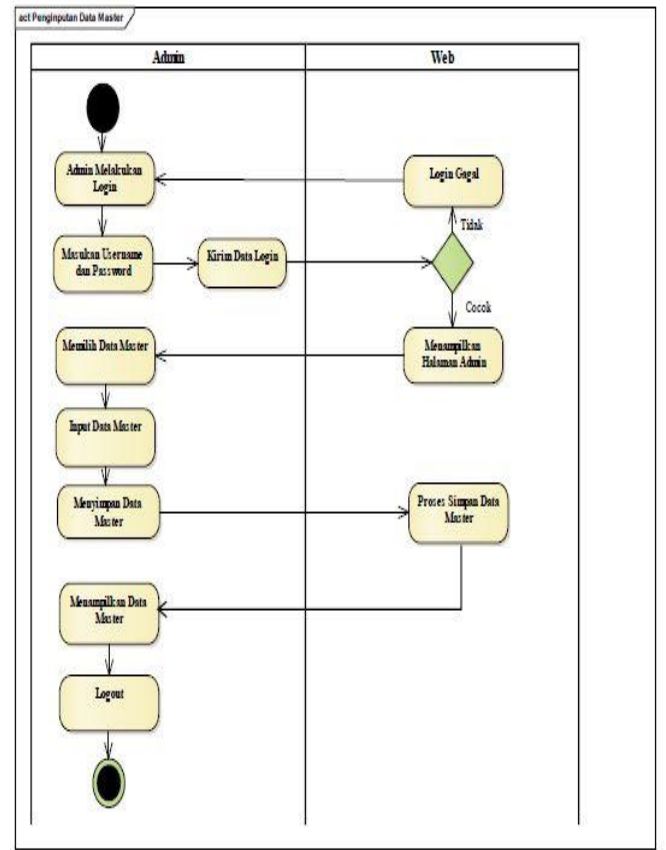

Gambar 5. Activity Diagram Penginputan Data Master

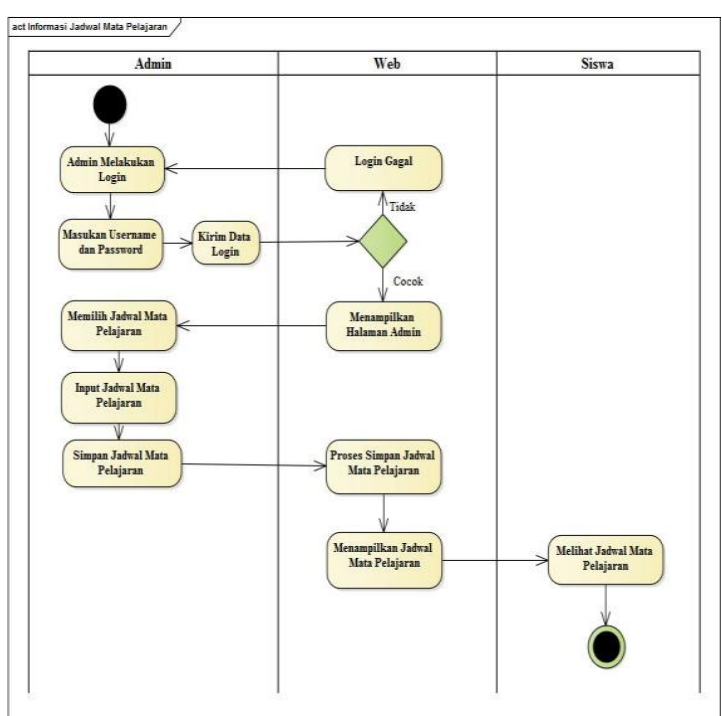

Gambar 6. Activity Diagram Informasi Jadwal Pelajaran

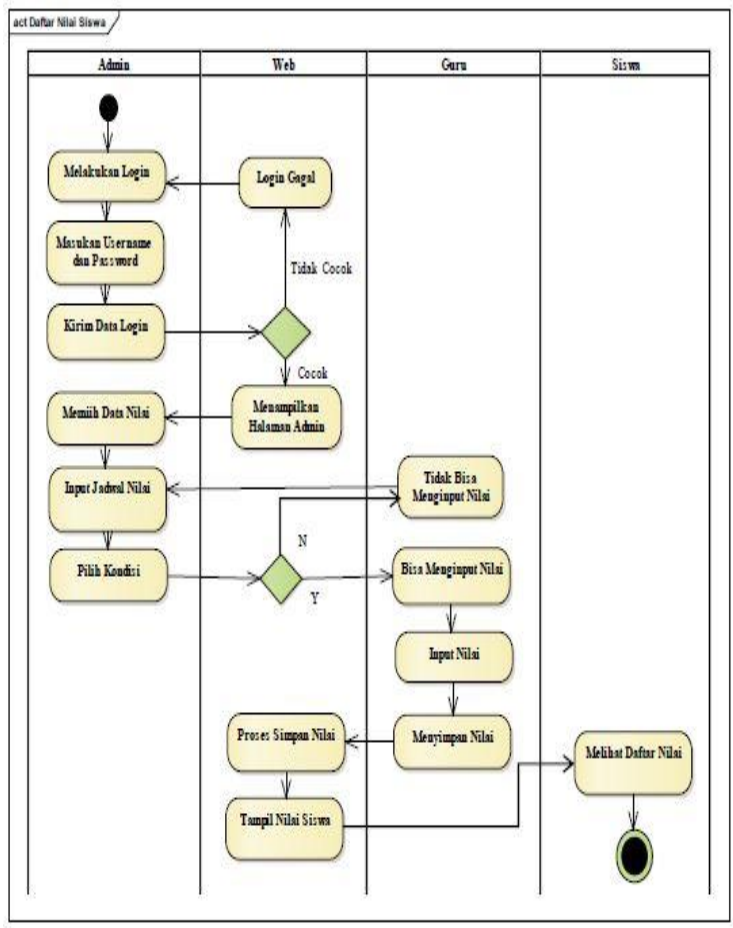

Gambar 7.Activity Diagram Informasi Daftar Nilai Siswa

D. Entity Relationship Diagram

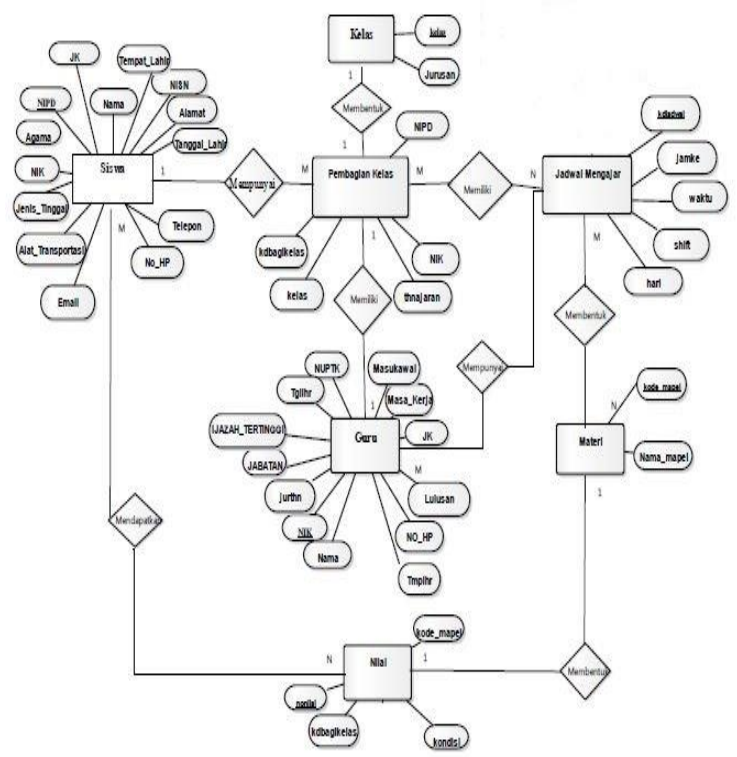

Gambar 8. Entity Relationship Diagram 
E. Logical Record Structure

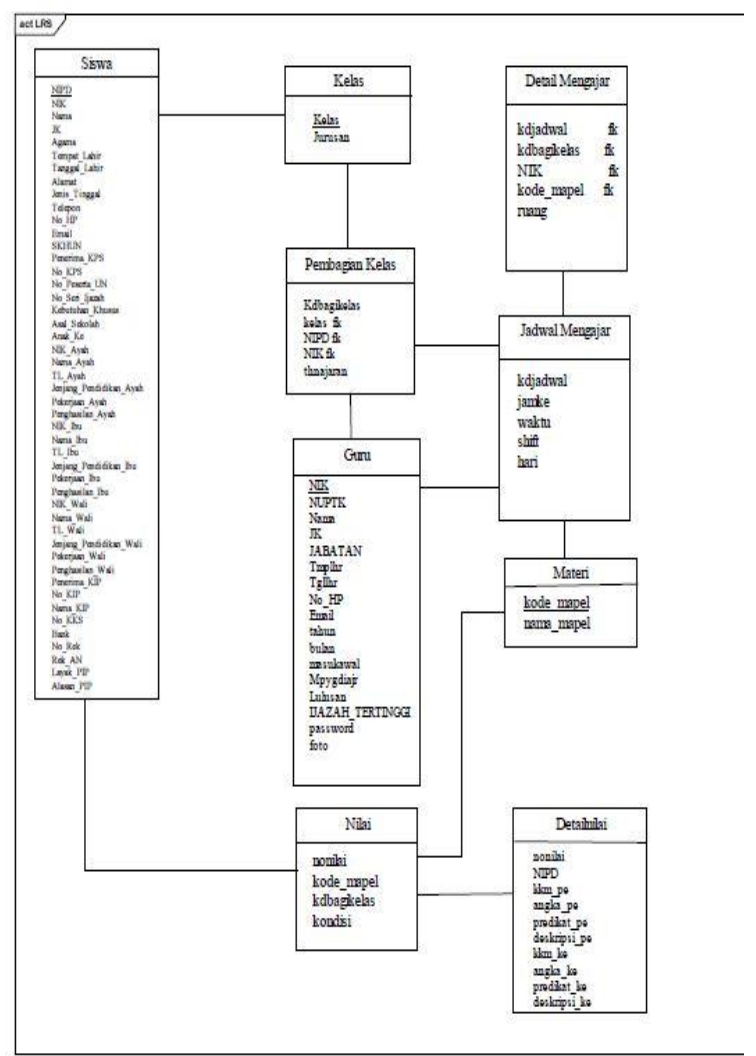

Gambar 9. Logical Record Structure

\subsection{User Interface}

User interface merupakan bentuk tampilan grafis yang berhubungan langsung dengan pengguna (user). Antarmuka pengguna berfungsi untuk menghubungkan antara pengguna dengan sistem operasi, sehingga komputer tersebut bisa digunakan.

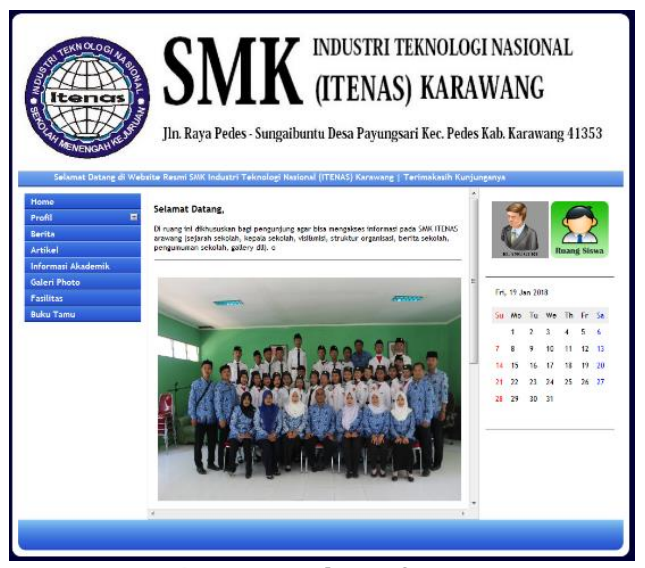

Gambar 10. User interface halaman Home Awal

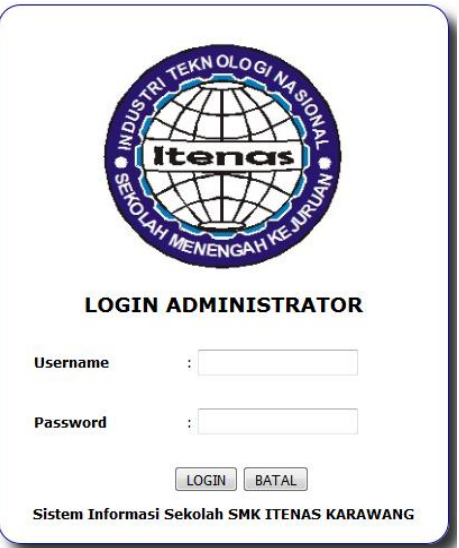

Gambar 11. User interface halaman Login Admin

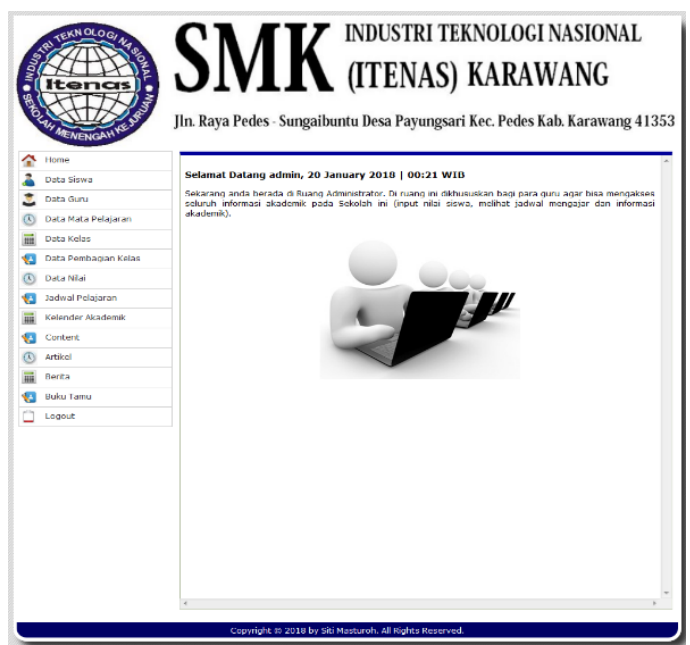

Gambar 12. User interface Tampilan Halaman Admin

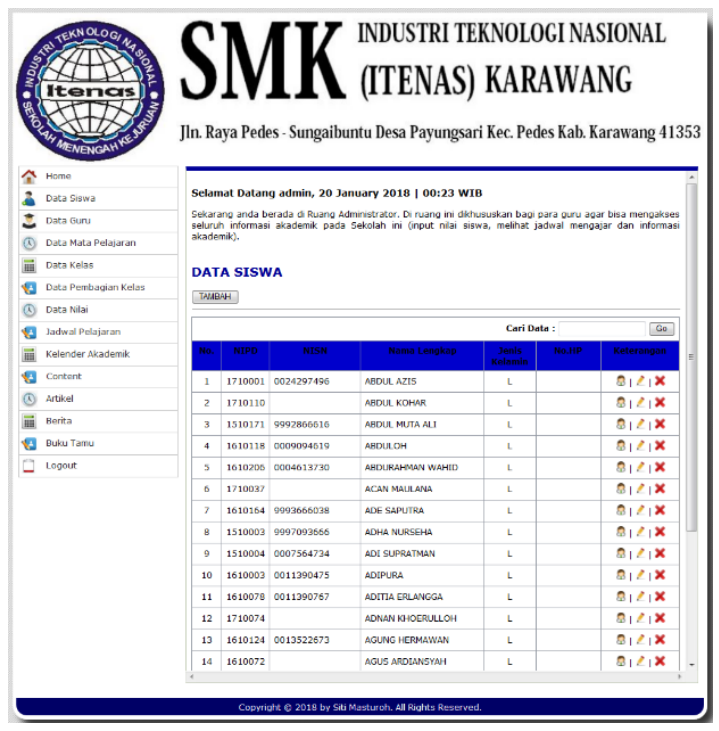

Gambar 13. User interface Tampilan Data Siswa 

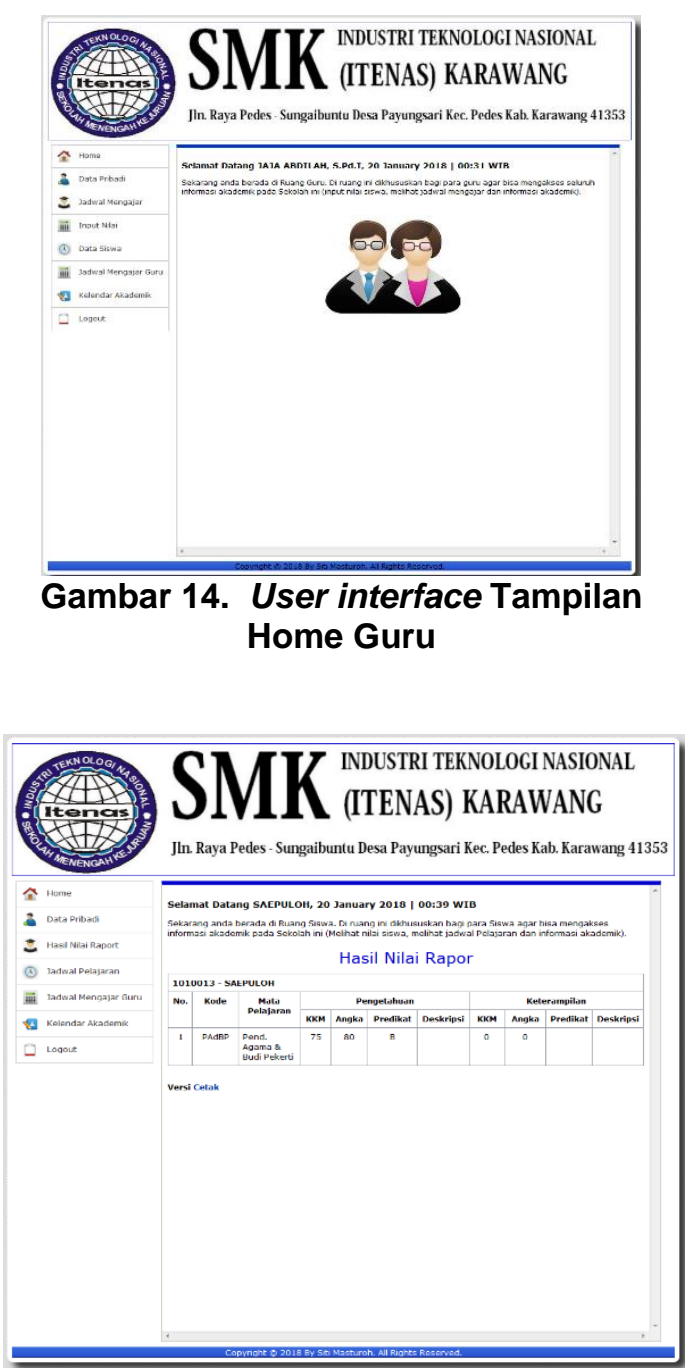

Gambar 15. User interface Tampilan Nilai Rapot

\section{Kesimpulan}

Program aplikasi sistem informasi akademik berbasis web pada SMK Industri Teknologi Nasional (ITENAS) karawang merupakan sarana komunikasi bagi siswa, guru dan pihak sekolah untuk memperoleh informasi mengenai segala sesuatu yang berhubungan dengan sistem proses belajar mengajar. Memberikan kemudahan kepada siswa untuk mendapatkan informasi mengenai kesiswaan, yaitu seperti jadwal pelajaran, nilai dan informasi-informasi terbaru yang diterbitkan oleh pihak sekolah. Peningkatan efisiensi dan efektifitas dalam pendistribusian informasi akademik kepada guru dan staff pengajar.

\section{Refensi}

Darmawan, Deni dan Kunkun Nur Fauzi.2013. Sistem Informasi Manajemen. Bandung: Rosda Karya.

Fathansyah.2012. Basis Data. Bandung : informatika bandung.

Irawan(a). 2011. Panduan Berinternet untuk orang awam. Palembang: Maxikom.

Irawan(b).2012.Javascript untuk Orang Awam.Palembang.Maxikom.

Pressman, Roger S. 2010. Sofware Engineering: $A$ Practitioner's Approach. New York: The McGraw-Hill Companies

Puspitawati, Lilis dan Sri dewi Anggadini. 2011. Sistem Informasi Akuntansi. Yogyakarta: Graha IImu.

Raharjo,Budi.2011.Belajar Otodidak Membuat Database Menggunakan MySQL. Bandung:Informatika Bandung.

Riyanto.2011.Membuat sendiri aplikasi ecommerce dengan PHP \& MySQL menggunakan Codelgniter \& JQuery.Yogyakarta:Andi.

S, Rosa A. dan M.Salahuddin.2015. Rekayasa Perangkat Lunak. Bandung:Informatika Bandung.

Saputra,Agus. 2012. Web Tips PHP,HTML5 dan CSS3. Jakarta: Jasakom.

Simarmata, Janner. 2010. Rekayasa Perangkat Lunak. Andi: Yogyakarta.

Sutarman.2012. "Pengantar Teknologi Informasi".Yogyakarta:Kanisius.

Winarno, Edy dan Ali Zaki, Smitdev Community. 2013. Buku sakti Pemrograman PHP. Jakarta: Elex Media Komputindo 